\title{
Cold Urticaria in a Pediatric Cohort: Clinical Characteristics, Management, and Natural History
}

\author{
Connor Prosty ${ }^{1}$, Sofianne Gabrielli ${ }^{1}$, Pasquale Mule ${ }^{1}$, Madison Le Gallee ${ }^{2}$, Laura May \\ Miles $^{1}$, Michelle Le ${ }^{1}$, Xun Zhang ${ }^{3}$, LUIS FELIPE ENSINA ${ }^{4}$, Elena Netchiporouk ${ }^{1}$, and \\ Moshe Ben-Shoshan ${ }^{2}$ \\ ${ }^{1}$ McGill University Health Centre \\ ${ }^{2}$ McGill University \\ ${ }^{3}$ Research Institute of the McGill University Health Centre \\ ${ }^{4}$ Universidade Federal de São Paulo
}

January 20, 2022

\begin{abstract}
Background Cold urticaria (coldU) is associated with substantial morbidity and risk of fatality. Data on coldU in children are sparse. We aimed to evaluate the clinical characteristics, management, risk of associated anaphylaxis, and resolution rate of coldU in a pediatric cohort. Additionally, we sought to compare these metrics to children with chronic spontaneous urticaria (CSU). Methods We prospectively enrolled children with coldU from 2013-2021 in a cohort study at the Montreal Children's Hospital and an affiliated allergy clinic. Data for comparison with participants with solely CSU were extracted from a previous study. Data on demographics, comorbidities, severity of presentation, management, and laboratory values were collected at study entry. Patients were contacted yearly to assess for resolution. Results Fifty-two children with cold urticaria were recruited, $51.9 \%$ were female and the median age of symptom onset was 9.5 years. Most patients were managed with second generation H1-antihistamines ( $\mathrm{sgAHs}$ ). Well-controlled disease on sgAHs was negatively associated with concomitant CSU (adjusted odds ratio $(\mathrm{aOR})=0.69$ [95\% CI: $0.53,0.92])$. Elevated eosinophils were associated with cold-induced anaphylaxis $($ coldA) $(\mathrm{aOR}=1.38$ [95\% CI: $1.04,1.83]$ ), which occurred in $17.3 \%$ of patients. The resolution rate of coldU was 4.8 per 100 patient-years, which was lower than that of CSU (adjusted hazard ratio=0.43 [95\%CI: 0.21, 0.89], P<10-2). Conclusion Pediatric coldU bears a substantial risk of anaphylaxis and a low resolution rate. Absolute eosinophil count and co-existing CSU may be useful predictive factors.
\end{abstract}

\section{Cold Urticaria in a Pediatric Cohort: Clinical Characteristics, Management, and Natural History}

Connor Prosty, BSc ${ }^{1}$, Sofianne Gabrielli, $\mathrm{MSc}^{2}$, Pasquale Mule, $\mathrm{BSc}^{2}$, Madison Le Gallee ${ }^{1}$, Laura May Miles, $\mathrm{LLM}^{2}$, Michelle Le, $\mathrm{MD}^{3}$, Xun Zhang, $\mathrm{PhD}^{4}$, Luis F. Ensina, MD PhD ${ }^{5}$, Elena Netchiporouk, MD $\mathrm{MSc}^{3}$, Moshe Ben-Shoshan, MD MSc${ }^{2}$

${ }^{1}$ Faculty of Medicine, McGill University, Montreal, QC, Canada.

${ }^{2}$ Division of Allergy, Immunology and Dermatology, Montreal Children's Hospital, Montreal, QC, Canada.

${ }^{3}$ Division of Dermatology, McGill University, Montreal, QC, Canada

${ }^{4}$ Centre for Outcomes Research and Evaluation, Research Institute of McGill University Health Centre, Montreal, QC, Canada.

${ }^{5}$ Division of Allergy, Clinical Immunology, and Rheumatology, Federal University of Sao Paulo, Brazil. 


\section{Corresponding author:}

Connor Prosty, B.Sc.

1001 Decarie Blvd, Montréal

Québec, H4A 3J1

Email: connor.prosty@mail.mcgill.ca

Phone: 514-934-1934 ext. 23151

Fax: 514-412-4390

Article Type: Original Manuscript

Funding Sources: This article has no funding source.

Conflict of Interest: Luis F. Ensina is a consultant and speaker for Novartis, Takeda, Sanofi and Abbvie and is involved in clinical trials with Novartis. Elena Netchiporouk is a consultant and speaker for Novartis and has received an investigator-initiated research grant from Novartis. Moshe Ben-Shoshan is a consultant for Novartis and Sanofi. The other authors declare no conflicts of interest.

Prior Presentation: An abstract based on part of the cohort of this article has been presented at the 2021 GA $^{2}$ LEN UCARE Conference.

Keywords: cold urticaria; cold-induced urticaria; pediatrics; chronic urticaria; chronic inducible urticaria; anaphylaxis

Manuscript word count: 2497

Abstract word count: 230

References: 29

Figures/Tables: 4

Supplemental Tables: 0

Reprint request: Reprints not available from the authors.

\section{ABBREVIATIONS}

\begin{tabular}{ll}
\hline CIndU & Chronic inducible urticaria \\
\hline ColdU & Cold urticaria \\
CU & Chronic urticaria \\
sgAH & Second generation H1-antihistamine \\
CSU & Chronic spontaneous urticaria \\
UCT & Urticaria control test \\
CRP & C-reactive protein \\
CBC & Complete blood count \\
ColdA & Cold-induced anaphylaxis \\
\hline
\end{tabular}

\section{KEY MESSAGE}

Concomitant chronic spontaneous urticaria may be a useful predictive factor for a poor response to antihistamines and eosinophilia may predict cold-induced anaphylaxis in children with cold urticaria. Patients with cold urticaria should be advised of low rate of spontaneous resolution.

\section{ABSTRACT}




\section{Background}

Cold urticaria (coldU) is associated with substantial morbidity and risk of fatality. Data on coldU in children are sparse. We aimed to evaluate the clinical characteristics, management, risk of associated anaphylaxis, and resolution rate of coldU in a pediatric cohort. Additionally, we sought to compare these metrics to children with chronic spontaneous urticaria (CSU).

\section{Methods}

We prospectively enrolled children with coldU from 2013-2021 in a cohort study at the Montreal Children's Hospital and an affiliated allergy clinic. Data for comparison with participants with solely CSU were extracted from a previous study. Data on demographics, comorbidities, severity of presentation, management, and laboratory values were collected at study entry. Patients were contacted yearly to assess for resolution.

\section{Results}

Fifty-two children with cold urticaria were recruited, $51.9 \%$ were female and the median age of symptom onset was 9.5 years. Most patients were managed with second generation H1-antihistamines (sgAHs). Well-controlled disease on sgAHs was negatively associated with concomitant CSU (adjusted odds ratio $(\mathrm{aOR})=0.69$ [95\%CI: $0.53,0.92])$. Elevated eosinophils were associated with cold-induced anaphylaxis (coldA) $(\mathrm{aOR}=1.38$ [95\% CI: 1.04, 1.83]), which occurred in $17.3 \%$ of patients. The resolution rate of coldU was 4.8 per 100 patient-years, which was lower than that of CSU (adjusted hazard ratio=0.43 [95\%CI: 0.21, $\left.0.89], \mathrm{P}<10^{-2}\right)$.

\section{Conclusion}

Pediatric coldU bears a substantial risk of anaphylaxis and a low resolution rate. Absolute eosinophil count and co-existing CSU may be useful predictive factors.

\section{INTRODUCTION}

Chronic inducible urticaria (CIndU) is a subset of chronic urticaria (CU) in which a specific trigger eliciting the hives is identified ${ }^{1}$. Cold urticaria (coldU) is a type of CIndU characterized by pruritic wheals and/or angioedema triggered by exposure to cold air, liquids, or objects ${ }^{2}$. The pathogenesis of coldU is not well understood. It is postulated that cold exposure triggers de novo autoantigen formation, which triggers IgE-mediated mast cell degranulation and release of inflammatory mediators leading to wheals and/or angioedema ${ }^{3}$. ColdU is the main type of CU known to cause anaphylaxis ${ }^{3}$.

The point prevalence of coldU is estimated to be $0.056 \%(95 \% \mathrm{CI}: 0.016,0.112)^{4}$, which may inversely correlate with the average temperature of the country of residence. The diagnosis of coldU consists of provocation testing using an ice cube or the TempTest, which determines the threshold temperature at which symptoms develop ${ }^{5}$. Treatment consists of avoiding cold triggers, second generation H1-antihistamines (sgAHs) up to four-times the standard dose, and, in recalcitrant cases, off-label use of omalizumab may be considered ${ }^{4,5}$. It is suggested that the resolution rate of coldU is low, with fewer than half (44.5\%) of adult patients experiencing symptom resolution in 10 years $^{6}$. Although coldU predominantly manifests in young adults, $27 \%$ of cases begin in childhood and these cases are less likely to experience symptom resolution ${ }^{6}$. Coldinduced anaphylaxis is reported in up to $36.7 \%$ of children with coldU ${ }^{7}$. However, there are scarce data published on pediatric coldU. We aimed to assess the clinical characteristics, comorbidities, management, risk of anaphylaxis, and natural history of coldU in a cohort of children. Additionally, we sought to compare the presentation and resolution rate of pediatric coldU to chronic spontaneous urticaria (CSU).

\section{METHODS}

\section{Enrolment and Questionnaires}

Children presenting with CU were consecutively recruited from 2013 to 2021 as part of our CU registry at the Montreal Children's Hospital and an affiliated pediatric allergy clinic. Written informed consent was obtained from the parents and/or legal guardians of study participants, and an assent form was obtained 
from children seven years and older. This registry was approved by the Centre for Applied Ethics from the McGill University Health Centre Research Ethics Board (REB 12-255 GEN, June 3, 2013). ColdU was diagnosed based on clinical history and wheal formation after five minutes of skin exposure to a plastic bag-wrapped ice cube ${ }^{5}$. The diagnosis of coldU also included cases with cold-induced symptoms (at least two episodes in history) in the absence of reaction to the ice cube test (atypical coldU). Patients were also assessed at study entry for concomitant CIndUs by clinical history and/or provocation testing, as well as for concomitant CSU. Data on coldU triggers were extracted from the patients' medical charts.

At study entry, we administered a standardized questionnaire querying on the patient's demographics, symptoms, comorbidities, family history, and management of their coldU. Beginning in 2018, participants completed the Urticaria Control Test (UCT) at study entry. Patients recruited prior to 2018, whose urticaria had not resolved, completed the UCT at follow-up. Children less than 12 years of age were permitted to complete the questionnaire and UCT with the help of their guardians, a score of at least 12 was considered well-controlled ${ }^{8}$.

\section{Natural History}

Resolution of coldU was defined as an absence of wheals and/or angioedema without treatment for at least one year ${ }^{9}$. All patients were followed annually to assess for resolution either through an in person or telephone-based standardized questionnaire. In case of loss of follow-up, we attempted to contact patients by phone and/or email at least five times per year.

\section{Laboratory Tests}

Consenting patients underwent additional blood tests for baseline IgE, tryptase, c-reactive protein (CRP), and a complete blood count (CBC). Absolute blood eosinophils, total IgE, tryptase, and CRP were considered as dichotomous variables. An absolute blood eosinophil value $>0.60 \times 10^{9}$ cells $/ \mathrm{L}$, total $\operatorname{IgE}$ level $>240 \mathrm{IU} / \mathrm{mL}$, tryptase $>13.5 \mathrm{ug} / \mathrm{mL}$, and CRP $>5 \mathrm{mg} / \mathrm{mL}$ were categorized as elevated based on the upper limit reference level for these biomarkers at the Montreal Children's Hospital.

\section{CSU Data}

To contrast pediatric coldU to CSU, we extracted data on demographics, comorbidities, and resolution rate of children solely with CSU (i.e., no co-existing CIndU) from a prior study using the same CU registry ${ }^{10}$.

\section{Statistical Analyses}

Statistical tests were performed using R software (2020, version 4.0.0, R Core Team, Vienna, Austria). Demographic, clinical characteristic, and management data were presented with descriptive statistics. A chi-squared test was used to compare proportions. Continuous variables were assessed by an independent two-samples T-test. Logistic regression was used to assess factors associated with coldA and well-controlled symptoms on sgAHs (UCT[?]12). Multivariate cox regression analysis was used to compare the resolution rate of coldU to CSU, using thesurvival and surviminer packages. A Kaplan-Meier curve of disease persistence was plotted using the ggplot2 package.

\section{RESULTS}

\section{Demographics and Comorbidities (Table 1)}

From 2013 to 2021 we approached all patients presenting to the Montreal Children's Hospital and the Children's Clinic with CU. All patients approached consented to study participation. We recruited a total of 52 children with coldU. Approximately half of the patients (51.9\%) were female and the median age at symptom onset was 9.5 years (interquartile range [IQR]: $4.8,13.0$ ).

Ice cube tests were performed in all patients and $90.4 \%$ of tests were positive. The remaining $9.6 \%$ of patients with negative tests had strong clinical histories consistent with coldU and were defined as atypical coldU. Importantly, no patients had clinical features or family histories indicative of cryopyrin-associated periodic syndromes or $P L C G 2$-associated antibody deficiency and immune dysregulation. 
Triggers of coldU were recorded in 38 patients' medical charts. Swimming was the most common trigger (76.3\%), followed by cold weather/air (65.8\%), and ingestion of cold food or drink (18.4\%). Angioedema in addition to hives was documented in $28.8 \%$ of patients.

Other concomitant types of CU were recorded in $48.1 \%$ of patients, consisting of $22(42.3 \%)$ with CSU and five $(9.6 \%)$ with cholinergic urticaria (of which two patients had concomitant cholinergic urticaria and CSU). Comorbid atopic diseases included asthma (30.8\%), atopic dermatitis (30.8\%), allergic rhinitis $(21.2 \%)$, food allergies $(9.6 \%)$, and venom allergies (1.9\%). Autoimmune diseases (celiac disease and type I diabetes mellitus) were documented in two $(3.8 \%)$ patients.

A first-degree family history of atopy was present in $15.4 \%$ of patients. Moreover, a family history of CU was recorded in $17.3 \%$ of patients, a third of which was coldU.

\section{ColdU Demographics Compared to CSU (Table 1)}

We extracted data on a total of 103 pediatric CSU patients from the Netchiporouk et al. study ${ }^{10}$. Median age of disease onset was 5.0 years (IQR: $2.0,10.0)$ and approximately half $(48.5 \%)$ of CSU patients were female. There was a significantly higher proportion of coldU patients with comorbid asthma $(\mathrm{P}=0.030)$, atopic dermatitis $(\mathrm{P}=0.012)$, and elevated $\operatorname{IgE}$ levels $(\mathrm{P}=0.010)$ compared to CSU patients. Mean age of onset was significantly higher in coldU patients $\left(\mathrm{P}<10^{-3}\right)$. No significant differences were identified in other demographics, comorbidities, or laboratory values.

\section{Management (Table 2)}

$\mathrm{SgAHs}$ were the predominant management strategy used in $94.2 \%$ of patients. Diphenhydramine was used during exacerbations in $30.8 \%$ of patients. A minority of patients $(5.8 \%)$ required short-term (up to one week) oral corticosteroids for treating exacerbations. Omalizumab was used by one (1.9\%) patient while also taking desloratadine. Finally, three patients (5.8\%) managed their symptoms without any medication by avoiding cold triggers.

The UCT was completed by 48 patients at study entry or at follow-up. Of patients managed with sgAHs, $56.8 \%$ had well-controlled UCT scores. When adjusting for age and sex, concomitant CSU was negatively associated with well-controlled disease on sgAHs (adjusted odds ratio [aOR] $=0.69$ [95\%CI: 0.53, 0.92], Table 3). All patients managed by cold avoidance alone had well-controlled UCT scores. Finally, the patient managed with omalizumab and desloratadine for a period of two years did not have a well-controlled score.

\section{Cold-Induced Anaphylaxis (ColdA)}

ColdA (defined as involvement of at least two different organs or systems or hypotension ${ }^{11}$ in response to a cold trigger) was recorded in $17.3 \%$ of patients. Symptoms of coldA were predominantly shortness of breath (44.4\%) and hypotension/syncope (44.4\%), and less commonly abdominal pain (22.2\%), headache (22.2\%), and fatigue (11.1\%). Triggers of coldA were swimming (44.4\%) or cold air (44.4\%) and one child (11.1\%) reported a history of coldA episodes triggered by both swimming and cold air. One patient (11.1\%) required treatment with an epinephrine autoinjector and no fatalities or hospitalizations from coldA were recorded. Elevated eosinophils were associated with a history of coldA (aOR=1.38 [95\%CI: 1.04, 1.83], Table 3), when controlling for sex and age.

\section{Resolution}

Of the 52 participants, four $(7.7 \%)$ participants were lost to follow-up. From study entry, patients were followed for a median of 2.6 years (IQR: 0.9, 5.6). Disease resolution was recorded in $12(25.0 \%)$ of the remaining 48 participants over 248.0 patient-years (4.8 cases of disease resolution per 100 patient-years). Among those whose disease resolved, median age at resolution was 9.0 years (IQR: 8.0, 15.5) and median disease duration was 3.5 years (IQR: 1.0, 7.0). Of those with persistent coldU, median disease duration was 5.3 years (IQR: 2.0, 8.0).

Data on disease resolution was available in all 103 CSU patients, of which $33(32.0 \%)$ resolved over 290 
patient-years (11.4 cases of resolution per 100 patient-years). Of those experiencing CSU resolution, median disease duration and age at disease resolution were 1.4 (IQR: 0.79, 2.1) and 9.0 (IQR: 4.9, 13.7) years, respectively. Median disease duration was 2.3 years (IQR: 1.6, 4.0) in patients with persistent CSU.

When controlling for age at disease onset and sex, multivariate cox regression analysis revealed that cases of coldU were significantly less likely to experience disease resolution than cases of CSU (adjusted hazard ratio: 0.43 [95\% CI: 0.21, 0.89], $\mathrm{P}<10^{-2}$, Figure 1 ).

\section{DISCUSSION}

We established that coldU in children has a lower resolution rate than CSU. Further, among children with coldU, $17.3 \%$ of patients experienced coldA, predominantly cases with elevated eosinophils.

Similar to prior studies, we found that pediatric coldU has no sex predilection ${ }^{12,13}$, unlike in adults where females make up the majority of cases ${ }^{6,14}$. The median age of onset of symptoms in our population $(9.5$ years) was consistent with other reports in children (7-8.5 years $)^{7,12,13}$.

We found that approximately half of patients had concomitant CU of other types, predominantly CSU, and a minority had cholinergic urticaria. A large retrospective study of coldU in children reported that only $14.2 \%$ and $3.6 \%$ of participants had concomitant CSU and cholinergic urticaria, respectively ${ }^{12}$. The elevated proportion of patients with concomitant CSU $(42.3 \%)$ and cholinergic urticaria (9.6\%) in our study may be because patients were assessed for concomitant types of CU at study entry. In line with our results, a study of both adults and children study reported that $8 \%$ of patients with cold urticaria had co-existent cholinergic urticaria $^{15}$.

Other studies suggest that co-existing atopic conditions may be more common. Yee et al. report that among children with coldU, $59.5 \%$ had concomitant allergic rhinitis, $46.8 \%$ had asthma, and $33.4 \%$ had food allergies ${ }^{12}$. However, the prevalence of atopic dermatitis among children with coldU was slightly lower than in the present study $(24.6 \% \text { versus } 30.8 \%)^{12}$. These differences may reflect geographic or ethnic differences between the studied populations ${ }^{16,17}$.

Relative to CSU, we found an increased proportion of coldU patients with IgE/Th2 mediated diseases (i.e., asthma and atopic dermatitis) and elevated total IgE. Consistent with these findings, the majority of CSU cases are associated with an autoimmune etiology consisting of auto-IgG or auto-IgE antibodies ${ }^{18,19}$, whereas coldU is predominantly an IgE mediated disease ${ }^{3}$. A Th2/IgE etiology underlying coldU indicates the potential therapeutic utility of $\operatorname{IgE}$ (i.e., omalizumab) and Th2 (i.e., dupilumab) inhibitors. Omalizumab efficacy in treating coldU refractory to antihistamines has been established in adults ${ }^{20}$, but not yet in children. A case report has documented the resolution of coldU and concomitant atopic dermatitis in an adult taking dupilumab $^{21}$, and a clinical trial is underway to determine its efficacy in adult coldU (NCT04681729). Dupilumab is already licenced for the treatment of atopic dermatitis in children; therefore, it may be a treatment option in children with both atopic dermatitis and coldU. Further studies are necessary to elucidate the role of $\mathrm{IgE}$ and the Th2 response in coldU.

Children in our cohort were predominantly managed with sgAHs, of which $56.8 \%$ of patients had wellcontrolled symptoms. Concomitant CSU was associated with poorly controlled disease on sgAHs. No clinical trials have assessed the efficacy of $\mathrm{sgAHs}$ in pediatric coldU ${ }^{22}$. However, several studies have found that sgAHs significantly diminish symptoms and decrease the minimum temperature at which symptoms develop in adults ${ }^{22-26}$. Further studies are required to establish the efficacy of sgAHs in the treatment of pediatric coldU, and to determine the usefulness of concomitant CSU as a predictor of $\operatorname{sgAH}$ response.

In this study, $17.3 \%$ of children had a history of coldA. This is in line with a recent meta-analysis conducted by our team that determined that the prevalence of anaphylaxis among cases of adult and pediatric coldU was $21.5 \%\left(95 \% \text { CI: } 15.8 \%, 28.5 \% ; \mathrm{I}^{2}=69 \%\right)^{4}$. Further, we identified that elevated blood eosinophils were associated with coldA. These results suggest that blood eosinophils may be used identify patients at risk for coldA, which can inform epinephrine autoinjector prescription and counselling of patients to avoid common triggers of coldA. A recent case report recorded the successful treatment of coldU and concomitant CSU with 
reslizumab, an anti-IL-5 monoclonal antibody, which downregulates eosinophil activation and recruitment ${ }^{27}$. However, little is known on the role of eosinophils in the pathogenesis of coldU/coldA.

The resolution of coldU in our cohort was fewer than 5 per 100 patient-years, almost half the resolution rate of $\mathrm{CSU}^{10}$. The resolution rate observed was similar to other studies that included both pediatric and adult patients (17.9-26.6\% of patients resolved in five years $)^{6,28}$. Because of insufficient sample size, we were unable to assess factors associated with disease resolution.

Our study has some potential limitations. This study had a relatively small sample size thereby limiting the power of subgroup analyses of participants with coldA and disease resolution. Our study was conducted at a tertiary urticaria referral center, which likely evaluates more severe cases of coldU that are refractory to antihistamines/involve anaphylaxis. However, we also recruited children from clinics outside the hospital and, hence, we believe that this study maintains external validity. Additionally, the wait time to see a specialist at our center is approximately four to eight months; therefore, our results may underestimate disease resolution because more self-limited cases were not recruited. Although we assessed all children with the UCT, it has not been validated for children under 12 years of age. However, the UCT is reported to have high validity and reliability in adults ${ }^{29}$ and preliminary work by our group supports its validity in children. Finally, we were unable to obtain follow-up data on four $(7.7 \%)$ of patients and certain lab values were not available in approximately a quarter of patients. However, given that data was available for most patients we do not expect these missing values to bias our results.

Taken together, our findings demonstrated a low resolution rate of pediatric coldU versus CSU. Elevated eosinophils were associated with anaphylaxis, which occurred in approximately one sixth of patients. Future multicentre studies are necessary to determine factors associated with coldU resolution.

\section{FIGURES AND TABLES}

Table 1. Patient characteristics, comorbidities, and lab values.

\begin{tabular}{|c|c|c|c|}
\hline Characteristics & $\begin{array}{l}\text { Cold Urticaria Total } \\
\text { No. }(\%)\end{array}$ & $\begin{array}{l}\text { Chronic Spontaneous } \\
\text { Urticaria Total No. } \\
\text { (\%) }\end{array}$ & P Value \\
\hline Demographics & Demographics & Demographics & Demographics \\
\hline Patients & 52 & 103 & $\mathrm{~N} / \mathrm{A}$ \\
\hline Female gender & $27(51.9)$ & $50(48.5)$ & 0.82 \\
\hline $\begin{array}{l}\text { Median age of } \\
\text { symptom onset in years } \\
\text { (IQR) }\end{array}$ & $9.5(4.8,13.0)$ & $5.0(2.0,10.0)$ & $\mathrm{N} / \mathrm{A}$ \\
\hline $\begin{array}{l}\text { Mean age of symptom } \\
\text { onset (SD) }\end{array}$ & $9.0(4.4)$ & $6.1(4.5)$ & $<10^{-3}$ \\
\hline Diagnostic Testing & Diagnostic Testing & Diagnostic Testing & Diagnostic Testing \\
\hline Ice cube test & $52(100.0)$ & $\mathrm{N} / \mathrm{A}$ & $\mathrm{N} / \mathrm{A}$ \\
\hline Positive ice cube test & $47(90.4)$ & $\mathrm{N} / \mathrm{A}$ & $\mathrm{N} / \mathrm{A}$ \\
\hline $\begin{array}{l}\text { Negative ice cube } \\
\text { test/Atypical cold } \\
\text { urticaria }\end{array}$ & $5(9.6)$ & $\mathrm{N} / \mathrm{A}$ & $\mathrm{N} / \mathrm{A}$ \\
\hline Triggers & Triggers & Triggers & Triggers \\
\hline Swimming & $28(73.7), \mathrm{N}=38$ & $\mathrm{~N} / \mathrm{A}$ & $\mathrm{N} / \mathrm{A}$ \\
\hline Weather/Air & $25(65.8), \mathrm{N}=38$ & $\mathrm{~N} / \mathrm{A}$ & $\mathrm{N} / \mathrm{A}$ \\
\hline Food & $7(18.4), \mathrm{N}=38$ & $\mathrm{~N} / \mathrm{A}$ & $\mathrm{N} / \mathrm{A}$ \\
\hline Comorbidities & Comorbidities & Comorbidities & Comorbidities \\
\hline $\begin{array}{l}\text { Other type of chronic } \\
\text { urticaria }\end{array}$ & $25(48.1)$ & $\mathrm{N} / \mathrm{A}$ & $\mathrm{N} / \mathrm{A}$ \\
\hline
\end{tabular}




\begin{tabular}{|c|c|c|c|}
\hline Characteristics & $\begin{array}{l}\text { Cold Urticaria Total } \\
\text { No. }(\%)\end{array}$ & $\begin{array}{l}\text { Chronic Spontaneous } \\
\text { Urticaria Total No. } \\
(\%)\end{array}$ & P Value \\
\hline $\begin{array}{l}\text { Chronic spontaneous } \\
\text { urticaria }\end{array}$ & $20(42.3)$ & $\mathrm{N} / \mathrm{A}$ & $\mathrm{N} / \mathrm{A}$ \\
\hline Cholinergic urticaria & $3(5.8)$ & $\mathrm{N} / \mathrm{A}$ & $\mathrm{N} / \mathrm{A}$ \\
\hline $\begin{array}{l}\text { Cholinergic and chronic } \\
\text { spontaneous urticaria }\end{array}$ & $2(3.8)$ & $\mathrm{N} / \mathrm{A}$ & $\mathrm{N} / \mathrm{A}$ \\
\hline Solar urticaria & $0(0.0)$ & $\mathrm{N} / \mathrm{A}$ & $\mathrm{N} / \mathrm{A}$ \\
\hline $\begin{array}{l}\text { Delayed pressure } \\
\text { urticaria }\end{array}$ & $0(0.0)$ & $\mathrm{N} / \mathrm{A}$ & $\mathrm{N} / \mathrm{A}$ \\
\hline Asthma & $16(30.8)$ & $15(14.6)$ & 0.030 \\
\hline Atopic dermatitis & $16(30.8)$ & $13(12.6)$ & 0.012 \\
\hline Allergic rhinitis & $11(21.2)$ & $9(8.7)$ & 0.054 \\
\hline Food allergies & $5(9.6)$ & $6(5.8)$ & 0.59 \\
\hline Autoimmune disease & $2(3.8)$ & $6(5.8)$ & 0.89 \\
\hline Celiac disease & $1(1.9)$ & $0(0.0)$ & 0.73 \\
\hline $\begin{array}{l}\text { Type I diabetes } \\
\text { mellitus }\end{array}$ & $1(1.9)$ & $2(1.9)$ & 1.0 \\
\hline IgA nephropathy & $0(0.0)$ & $1(0.97)$ & 1.0 \\
\hline $\begin{array}{l}\text { Autoimmune thyroid } \\
\text { disease }\end{array}$ & $0(0.0)$ & $2(1.9)$ & 0.80 \\
\hline Lupus & $0(0.0)$ & $1(0.97)$ & 1.0 \\
\hline Insect venom allergies & $1(1.9)$ & $3(2.9)$ & 1.0 \\
\hline $\begin{array}{l}\text { Autoinflammatory } \\
\text { disease }\end{array}$ & $0(0.0)$ & $\mathrm{N} / \mathrm{C}$ & $\mathrm{N} / \mathrm{A}$ \\
\hline Family History & Family History & Family History & Family History \\
\hline Atopy & $8(15.4)$ & $22(21.3)$ & 0.50 \\
\hline Chronic urticaria & $9(17.3)$ & $12(11.7)$ & 0.80 \\
\hline Cold urticaria & $3(5.8)$ & $\mathrm{N} / \mathrm{C}$ & $\mathrm{N} / \mathrm{A}$ \\
\hline Symptoms & Symptoms & Symptoms & Symptoms \\
\hline Angioedema & $15(28.8)$ & $24(23.3)$ & 0.58 \\
\hline $\begin{array}{l}\text { Cold-induced } \\
\text { anaphylaxis }\end{array}$ & $9(17.3)$ & $\mathrm{N} / \mathrm{A}$ & $\mathrm{N} / \mathrm{A}$ \\
\hline Laboratory Values & Laboratory Values & Laboratory Values & Laboratory Values \\
\hline $\begin{array}{l}\text { Tryptase } \\
(>13.5 \mathrm{ug} / \mathrm{mL})\end{array}$ & $1(2.3), \mathrm{N}=43$ & $0(0.0), \mathrm{N}=96$ & 0.68 \\
\hline $\operatorname{IgE}(>240 \mathrm{IU} / \mathrm{mL})$ & $25(64.1), \mathrm{N}=39$ & $34(37.8), \mathrm{N}=90$ & 0.010 \\
\hline $\mathrm{CRP}(>5 \mathrm{mg} / \mathrm{L})$ & $2(4.8), \mathrm{N}=42$ & $8(8.7), \mathrm{N}=92$ & 0.65 \\
\hline $\begin{array}{l}\text { Blood eosinophils } \\
\left(>0.60 \times 10^{9} / \mathrm{L}\right)\end{array}$ & $7(15.6), \mathrm{N}=45$ & $6(6.0), \mathrm{N}=100$ & 0.12 \\
\hline
\end{tabular}

N/A: Not applicable

N/C: Data not collected

Table 2. Urticaria Control Test (UCT) scores at study entry or at earliest follow-up by medication (N=48).

\begin{tabular}{llll}
\hline Medication & N & Well-Controlled UCT Score ([?]12) No. (\%) & IQR of UCT Score \\
\hline Second generation H1-antihistamines & 44 & $25(56.8)$ & $8.0,13.0$ \\
Cetirizine & 24 & $16(66.6)$ & $8.8,14.0$
\end{tabular}




\begin{tabular}{llll}
\hline Medication & N & Well-Controlled UCT Score ([?]12) No. (\%) & IQR of UCT Score \\
\hline Rupatadine & 11 & $3(27.2)$ & $8.3,11.8$ \\
Desloratadine & 6 & $3(50.0)$ & $8.8,12.8$ \\
Fexofenadine & 1 & $1(100.0)$ & 12 \\
Bilastine & 1 & $1(100.0)$ & 14 \\
Loratadine & 1 & $1(100.0)$ & 12 \\
Cold avoidance only & 3 & $3(100.0)$ & $6.5,12.0$ \\
Omalizumab and desloratadine & 1 & $0(0.0)$ & 7 \\
\hline
\end{tabular}

Table 3. Univariable and multivariable logistic regression of factors associated with well-controlled disease on second generation H1-antihistamines, cold-induced anaphylaxis, and disease resolution.

\begin{tabular}{lll}
\hline Variable & Well-Controlled Disease (UCT[?]12) on sgAHs & Well-Controlled Disease (UCT[?] \\
\hline & Univariate OR (95\% CI) & Multivariate OR (95\% CI) \\
Sex & $0.98(0.73,1.32)$ & $0.95(0.72,1.25)$ \\
Age at symptom onset & $0.97(0.94,1.00)$ & - \\
Age at study entry & $0.98(0.94,1.01)$ & $0.98(0.95,1.01)$ \\
Cold-induced Anaphylaxis & $0.93(0.63,1.38)$ & - \\
Elevated eosinophils & $1.00(0.66,1.51)$ & - \\
Elevated IgE & $0.87(0.61,1.22)$ & $0.69(0.53,0.92)^{*}$ \\
Concomitant CSU & $0.69(0.52,0.90)^{*}$ & - \\
Atopic dermatitis & $0.97(0.71,1.33)$ & - \\
Asthma & $1.07(0.78,1.46)$ & - \\
Allergic rhinitis & $1.05(0.66,1.69)$ & - \\
Trigger: Swimming & $0.84(0.55,1.29)$ & - \\
Trigger: Air & $0.92(0.63,1.33)$ & - \\
Trigger: Food/Drink & $0.90(0.58,1.42)$ &
\end{tabular}

*: $\mathrm{p}<0.05$ was considered significant

-: Cells not included in the multivariate logistical regression model.

N/A: Not applicable

Figure 1. Kaplan-Meier curve of disease resolution in cases of chronic spontaneous urticaria (orange) versus cold urticaria (blue). Cold urticaria was associated with a longer time to disease resolution when adjusting for sex and age at disease onset (Adjusted Hazard Ratio: 0.43 [95\%CI: 0.21, 0.89], $\mathrm{P}<10^{-2}$ ). Confidence intervals are represented by the corresponding dashed lines.

\section{REFERENCES}

1. Maurer M, Hawro T, Krause K, et al. Diagnosis and treatment of chronic inducible urticaria. Allergy. 2019;74(12):2550-2553.

2. Magerl M, Altrichter S, Borzova E, et al. The definition, diagnostic testing, and management of chronic inducible urticarias - The EAACI/GA(2) LEN/EDF/UNEV consensus recommendations 2016 update and revision. Allergy. 2016;71(6):780-802.

3. Maltseva N, Borzova E, Fomina D, et al. Cold urticaria - What we know and what we do not know. Allergy. 2021;76(4):1077-1094.

4. Prosty C, Gabrielli S, Le M, et al. Prevalence, Management and Anaphylaxis Risk of Cold Urticaria: A Systematic Review and Meta-Analysis. J Allergy Clin Immunol Pract. 2021. 
5. Magerl M, Altrichter S, Borzova E, et al. The definition, diagnostic testing, and management of chronic inducible urticarias - The EAACI/GA2LEN/EDF/UNEV consensus recommendations 2016 update and revision. Allergy. 2016;71(6):780-802.

6. Deza G, Brasileiro A, Bertolín-Colilla M, Curto-Barredo L, Pujol RM, Giménez-Arnau AM. Acquired cold urticaria: Clinical features, particular phenotypes, and disease course in a tertiary care center cohort. $J$ Am Acad Dermatol. 2016;75(5):918-924.e912.

7. Alangari AA, Twarog FJ, Shih M-C, Schneider LC. Clinical Features and Anaphylaxis in Children With Cold Urticaria. Pediatrics.2004;113(4):e313.

8. Park YM, Oh MS, Kwon JW. Predicting inadequate treatment response in children with chronic spontaneous urticaria. Pediatr Allergy Immunol. 2020;31(8):946-953.

9. Miles LM, Gabrielli S, Le M, et al. Clinical Characteristics, Management, and Natural History of Chronic Inducible Urticaria in a Pediatric Cohort. Int Arch of Allergy Immunol. 2021.

10. Netchiporouk E, Sasseville D, Moreau L, Habel Y, Rahme E, Ben-Shoshan M. Evaluating Comorbidities, Natural History, and Predictors of Early Resolution in a Cohort of Children With Chronic Urticaria.JAMA Dermatol. 2017;153(12):1236-1242.

11. Sampson HA, Muñoz-Furlong A, Campbell RL, et al. Second symposium on the definition and management of anaphylaxis: summary report-Second National Institute of Allergy and Infectious Disease/Food Allergy and Anaphylaxis Network symposium. J Allergy Clin Immunol.2006;117(2):391-397.

12. Yee CSK, El Khoury K, Albuhairi S, Broyles A, Schneider L, Rachid R. Acquired Cold-Induced Urticaria in Pediatric Patients: A 22-Year Experience in a Tertiary Care Center (1996-2017). J Allergy Clin Immunol Pract. 2019;7(3):1024-1031.e1023.

13. Bal F, Kahveci M, Soyer O, Sekerel BE, Sahiner UM. Chronic inducible urticaria subtypes in children: Clinical features and prognosis.Pediatr Allergy Immunol. 2021;32(1):146-152.

14. Paulino M, Costa C, Neto M, Pedro E. Cold Urticaria. Characterizing the Population From an Urticaria Outpatient Clinic. Actas Dermosifiliogr. 2021.

15. Neittaanmäki H. Cold urticaria: Clinical findings in 220 patients.

\section{$J$ Am Acad Dermatol}

1985;13(4):636-644.

16. Suaini NHA, Tan CPT, Loo EXL, Tham EH. Global differences in atopic dermatitis. Pediatr Allergy Immunol. 2021;32(1):23-33.

17. Wertenteil S, Strunk A, Garg A. Prevalence estimates for chronic urticaria in the United States: A sexand age-adjusted population analysis. J Am Acad Dermatol. 2019;81(1):152-156.

18. Kolkhir P, Church MK, Weller K, Metz M, Schmetzer O, Maurer M. Autoimmune chronic spontaneous urticaria: What we know and what we do not know. J Allergy Clin Immunol. 2017;139(6):1772-1781.e1771.

19. Fiebiger E, Hammerschmid F, Stingl G, Maurer D. Anti-FcepsilonRIalpha autoantibodies in autoimmunemediated disorders. Identification of a structure-function relationship. J Clin Invest. 1998;101(1):243-251.

20. Metz M, Schütz A, Weller K, et al. Omalizumab is effective in cold urticaria-results of a randomized placebo-controlled trial. J Allergy Clin Immunol. 2017;140(3):864-867.e865.

21. Ferrucci S, Benzecry V, Berti E, Asero R. Rapid disappearance of both severe atopic dermatitis and cold urticaria following dupilumab treatment. Clin Exp Dermatol. 2020;45(3):345-346.

22. Kulthanan K, Hunnangkul S, Tuchinda P, et al. Treatments of cold urticaria: A systematic review. $J$ Allergy Clin Immunol.2019;143(4):1311-1331. 
23. Magerl M, Pisarevskaja D, Church MK, Maurer M, Staubach P, Martus P. Critical temperature threshold measurement for cold urticaria: A randomized controlled trial of H1-antihistamine dose escalation. $\mathrm{Br} J$ Dermatol. 2012;166(5):1095-1099.

24. Krause K, Spohr A, Zuberbier T, Church MK, Maurer M. Up-dosing with bilastine results in improved effectiveness in cold contact urticaria.Allergy. 2013;68(7):921-928.

25. Abajian M, Krause K, Church MK, et al. Rupatadine $20 \mathrm{mg}$ and $40 \mathrm{mg}$ are effective in reducing the symptoms of chronic cold urticaria.Acta Derm Venereol. 2016;96(1):56-59.

26. Metz M, Scholz E, Ferrán M, Izquierdo I, Giménez-Arnau A, Maurer M. Rupatadine and its effects on symptom control, stimulation time, and temperature thresholds in patients with acquired cold urticaria.Ann Allergy Asthma Immunol. 2010;104(1):86-92.

27. Maurer M, Altrichter S, Metz M, Zuberbier T, Church MK, Bergmann KC. Benefit from reslizumab treatment in a patient with chronic spontaneous urticaria and cold urticaria. J Eur Acad Dermatol Venereol.2018;32(3):e112-e113.

28. Jain SV, Mullins RJ. Cold urticaria: a 20-year follow-up study.J Eur Acad Dermatol Venereol. 2016;30(12):2066-2071.

29. Weller K, Groffik A, Church MK, et al. Development and validation of the Urticaria Control Test: a patient-reported outcome instrument for assessing urticaria control. J Allergy Clin Immunol.2014;133(5):1365-1372, 1372.e1361-1366.

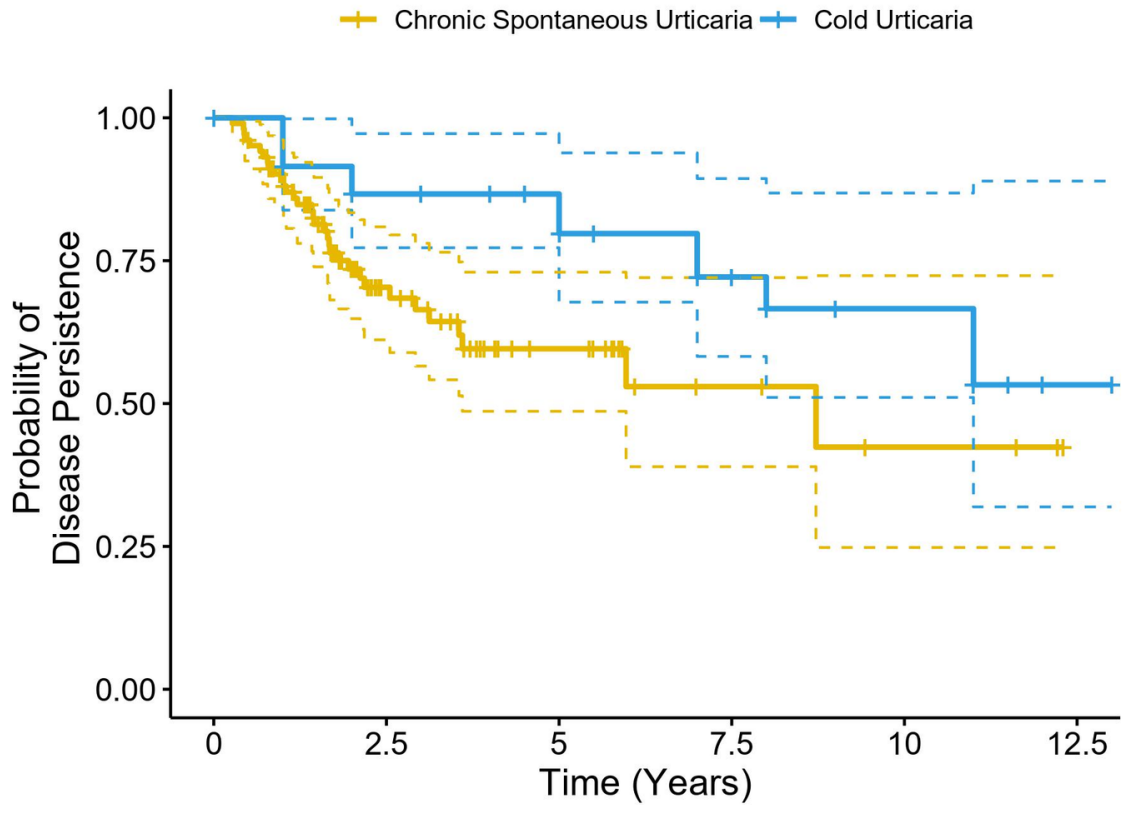

Number at risk
-\begin{tabular}{|cccccc}
103 & 37 & 16 & 6 & 3 & 0 \\
48 & 31 & 25 & 14 & 5 & 1 \\
\hline 0 & 2.5 & 5 & 7.5 & 10 & 12.5 \\
\hline & & Time (Years) & &
\end{tabular}

